\title{
Sports activities during any pandemic lockdown
}

\author{
Michael Anthonius $\operatorname{Lim}^{1}$ (D) $\cdot$ Raymond Pranata $^{1}$ (D)
}

Received: 17 June 2020 / Accepted: 1 July 2020 / Published online: 4 July 2020

(C) Royal Academy of Medicine in Ireland 2020

The coronavirus disease 2019 (COVID-19) pandemic forced the world's population to alter daily routines, including exercise habits. This unusual situation has physical, psychological, and behavioral consequences to all individuals, including elite and recreational athletes. Life in lockdown has been difficult because everyone has to stay safe and healthy, while at the same time abiding by new norms. Currently, mitigation strategies have been widely implemented to contain the spread of COVID-19. These measures include lockdown, social distancing, personal protective measures, and environmental and surface cleaning [1]. Furthermore, the practice of physically active lifestyles is recommended to counteract health and mental consequences of the COVID-19 pandemic [2]. While sedentary behavior certainly has no effect on the immunity, exercising in moderation is associated with improved immune competency and a reduced risk of illness. Overtraining and high-intensity exercise induce transient immune dysfunction and are associated with a greater risk of illness, including upper respiratory tract infections, but this may not apply to elite sportsmen [3, 4].

Post-exercise immune depression, especially after a strenuous training, may be explained by an impaired cell-mediated immunity [5]. Various modalities, such as soccer, football, and triathlons, are considered high-intensity sports. Consequently, these activities lead to an open window of susceptibility to infection [6]. The introduction of the new routines in the context of COVID-19 will allow certain outdoor exercises, which facilitate SARS-CoV-2 (severe acute respiratory syndrome coronavirus 2) transmission due to increased ventilation rates during exercise and possible mass gathering at sporting venues, stadiums, jogging tracks, parks, or any recreational areas. Currently, there are

Michael Anthonius Lim

lim.michael.a@gmail.com

Raymond Pranata

raymond_pranata@hotmail.com

1 Faculty of Medicine, Universitas Pelita Harapan,

Tangerang, Indonesia no solid guidelines regarding the use of face masks for outdoor exercises during the COVID-19 pandemic. We advise people to wear face masks during low to moderate-intensity exercises outside such as brisk walking and jogging, while maintaining a safe physical distance ( $2 \mathrm{~m}$ away) and personal hygiene in public. However, the use of face masks may compromise breathing and oxygen uptake in high-intensity, which are not recommended during these times.

With the resumption of normal life during COVID-19 taking effect immediately, guidelines for outdoor exercise, recreational activities, and returning to competitive sports must be enacted with caution. To help delay and mitigate COVID-19 spread, staying at home is still encouraged and the Centers for Disease Control and Prevention (CDC) recommends daily physical activity for both children (60 $\mathrm{min} /$ day) and adults (30 $\mathrm{min} /$ day). Each sport and activity is categorized by risk, but the general classification is (1) low risk: exercise at home, alone or with shared household members, with owned and sanitized equipment; (2) medium risk: exercise at public, alone or with shared household members no more than 5 people, with own and sanitized equipment; and (3) group exercise with non-household members in private or public, not physically distant, with shared equipment [7].

The risk of opportunistic infection is more likely to be influenced by the pre-exercise physical, nutritional, and psychological well-being. It is known that regular and frequent exercise enhances rather than suppresses the immune response in individuals of all ages, and thus protects them from infections [8]. In addition to exercise, appropriate immunenutritional support as well as proper management of psychological stress and sleep hygiene can reduce infection risk [5, 9]. Adoption of a proper diet and physical activity will eventually boost immunity (immune activation, immunosenescence, and vaccination efficacy) and metabolic systems (obesity, diabetes, and metabolic syndrome) [10].

During the self-isolation period, the majority of people grew accustomed to a sedentary lifestyle with less physical activity, fewer daily step counts, and rarely exercise, while athletes and certain people train individually to keep themselves fit and healthy [11]. Returning to normal exercise and 
sports activities is set to be a fascinating yet challenging time. In fact, many formerly fit individuals struggle to achieve their previous physical performance when stepping out to exercise in the age of COVID-19. Detraining or a prolonged break from training leads to the deconditioning of physiological systems (e.g., musculoskeletal, neuromuscular, respiratory, and cardiovascular systems) as well as physical capabilities (e.g., power, strength, flexibility, speed, and endurance) [12]. A randomized clinical trial by Kramer et al. [13] found that healthy adults with no physical activity have significantly lower aerobic capacity and lean mass compared with their counterparts who performed three minutes of hopping exercise, six days per week, for 60 days. In addition, the bone mineral density, knee extension strength, knee flexion strength, and peak power output of the bed-rest group are significantly reduced, while the jumping group preserved these parameters.

COVID-19 caused the suspension of sporting events, closure of gyms and fitness centers, and restrictions on outdoor activities. These factors led athletes to modify their exercise programs and train at home, most of which are not supervised by medical staff or coaches. Several athletes have a mini gym and/or fitness equipment at home to train individually. During this period, their aim should be to maintain or at least not lose their current fitness level [14]. The use of telehealth or other audiovisual-guided sessions for expert opinions is also useful during this difficult time. Cooperation with a multidisciplinary team involving medical staff, nutritionists, coaches, trainers, and psychologists can help athletes manage all the factors that influence performance, including physical conditioning, nutrition, hydration, sleep quality, and mindset.

Assuming a reduction in strength, flexibility, endurance, proprioceptive, and neuromuscular control, there is a greater risk of injury faced by athletes when transitioning from an unprecedented lockdown to high-level sports-specific practice. Learning from the National Football League (NFL) lockout in 2011 [15], following the premature transition from the end of lockout to the beginning of competitive fixtures, there was an unprecedented number of Achilles tendon ruptures during the training camp and preseason. Two-thirds of the players who ruptured their Achilles tendon returned to play in the NFL after Achilles tendon repair and around 11 months of rehabilitation, while the rest never went back to competition. These injuries likely represent career-changing and frequently career-ending moments for professional athletes. Despite maximum efforts from the club medical staff, there was a higher relative risk of reinjury during resumption of a full-contact training, pointing to lingering neuromuscular deficits in the athletes (Table 1).

COVID-19 lockdown can have similar impacts on other team-sports competitions. For example, soccer-specific training necessitates acceleration and deceleration, changes in direction, and chasing the ball at full speed. To date, blisters and minor injuries have been reported by a number of players following the return-to-pitch training, and we may see an increase in loadrelated problems (e.g., hamstrings, adductors, Achilles tendons, and patella tendons) and more serious injuries (e.g., ligaments and meniscuses) in the future. Zone7, an artificial intelligence platform specialized in predicting injury risk, conducted research in the English Premier League, which suggested an increase in injury incidence by $25 \%$ due to a congested schedule (eight matches plus training in 30 days) [16]. Therefore, the return to training and competitive action must be gradual, accompanied by regular risk assessment, and preceded by sports-specific medical assessment. Four phases have been suggested, beginning with small group training, then entire team training, followed by national league competition, and finally international competitions. Each player must be tested negative in two successive RT-PCR (reverse transcription polymerase chain reaction) SARS-CoV-2 pharyngeal swabs over a five-day interval, followed by continuous tests and monitoring [17-19]. Functional movement, maximal oxygen consumption $\left(\mathrm{VO}_{2} \mathrm{max}\right)$, and lactic threshold heart rate (LTHR) should be evaluated to help stratify the risk of injury and fatigue and indicate the level of current performance based on biomechanical, aerobic, and anaerobic capacity [20-22].

For healthy individuals, prolonged sitting during work or stay at home should be avoided while incorporating a healthy diet and physically active lifestyle into their daily routines is encouraged [23]. Sedentarism negatively impacts neuromuscular system (rapid muscle wasting, nerve fibers degeneration, and neuromuscular junction damage), muscle protein metabolism (suppression of muscle protein synthesis and upregulation of protein breakdown), impaired glucose homeostasis (reduced insulin sensitivity), cardiorespiratory system (reduced aerobic capacity), and energy balance (excessive fat deposition, systemic inflammation, and antioxidant activation) [24]. Besides maintaining productivity, their goal should be to avoid unnecessary weight gain and adopt a healthier and more sustainable lifestyle as a habit. At present, virtual gym classes and personal coaching are widely available online, while appointments for medical consultation are within the fingertips of the general population. With a more flexible schedule, healthy individuals can adjust their exercise modality, frequency, volume, and intensity with home-based exercises [2]. They must know their limits and abstain from any forms of exhaustive, strenuous, or high-intensity training, which can compromise the immune system. Meanwhile, moderateintensity endurance training and resistance training are recommended to boost immunity and maintain fitness and health. With all these options, the COVID-19 pandemic and related restrictions should no longer be an excuse for not maintaining a physically active lifestyle.

Older individuals and those with underlying comorbidities, such as hypertension, diabetes, cardiovascular and cerebrovascular diseases, coagulopathy, kidney and liver problems, and chronic lung disease, are categorized as high-risk groups 
Table 1 Insights for athletes, healthy individuals, and high-risk individuals

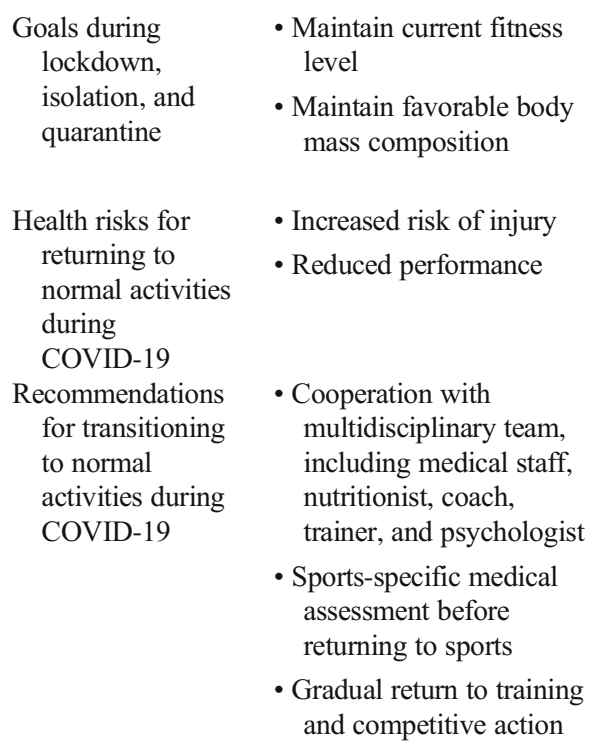

Consequences of physical inactivity or detraining

\begin{tabular}{ll}
\hline & Athletes \\
\hline $\begin{array}{l}\text { Problems caused } \\
\text { by the }\end{array}$ & $\begin{array}{c}\text { No competition and game } \\
\text { or match }\end{array}$ \\
demic & No team or group training \\
& $\cdot$ Reduced access to \\
& training facilities \\
& Train at home, mostly \\
& unsupervised \\
Consequences of & Declined physiological \\
physical & functions (e.g., \\
inactivity or & musculoskeletal, \\
detraining & neuromuscular, \\
& respiratory, and \\
& cardiovascular system) \\
& Deconditioned physical \\
& capabilities (e.g., power, \\
& strength, flexibility, \\
& speed, and endurance)
\end{tabular}

- Maintain productivity

- Avoid unnecessary weight gain

- Adopt a physically active lifestyle

- Develop chronic diseases

- Increased mortality and morbidity

- Avoid prolonged sitting during working or staying at home

- Adopt a physically active lifestyle

- Perform home-exercise and adjust the modality, frequency, volume, and intensity based on individual capability

- Avoid high-intensity exercise and aim for moderate-intensity endurance and resistance exercise
High-risk individuals

- Adverse health and mental consequences

- Risk of sedentary behavior and physical inactivity

- Unfavorable body mass composition (decreased muscle mass and increased fat mass)

- Deteriorated mobility

- Decreased performance of ADLs (e.g., eating, dressing, showering, toileting, and stair climbing)

- Developing health complications from comorbidities (e.g., myocardial infarction and pulmonary emboli)

- Developing mental issues (e.g., depression and anxiety)

- Preserve performance of ADLs

- Maintain quality of life

- Increased mortality and morbidity

- Increased risk of fall

- Decreased quality of life

- Perform ADLs independently if possible

- Perform multicomponent home-exercise involving strength, aerobic, balance, and coordination

- Use telehealth instead of medical visit to healthcare facility

- Social interaction to improve compliance and reduce the risk of mental issues

$A D L s$, activities of daily living

for contracting severe COVID-19 [25-32]. Under such a pandemic, they are forced into social isolation and quarantine at home, and most of these individuals are being physically inactive and mentally stressed (e.g., depression and anxiety) [33]. This may eventually increase the risk of mortality and morbidity in this group. These high-risk individuals should 
aim to preserve their performance of activities of daily living (ADLs), such as eating, dressing, showering, toileting, and stair climbing. Home-exercise using various safe, simple, and easily applicable training methods is well suited to maintain fitness levels while and avoiding airborne COVID-19 [34]. A multicomponent exercise program that includes strength, aerobic, balance, and coordination training is considered the best fit for elderly [2]. The addition of social elements to improve compliance and reduce the risk of mental problems is feasible with the support by internet, media, and audiovisual technology. Considering the availability of telehealth in many medical specialties, people with advanced age and chronic diseases can consistently access this internet-based service. Telerehabilitation will undoubtedly help most chronically disabled individuals to exercise at home in an effective yet sustainable way [35].

\section{Compliance with ethical standards}

Conflict of interest The authors declare that they have no conflict of interest.

\section{References}

1. Nieman DC (2020) Coronavirus disease-2019: a tocsin to our aging, unfit, corpulent, and immunodeficient society. J Sport Heal Sci. https://doi.org/10.1016/j.jshs.2020.05.001

2. Jiménez-Pavón D, Carbonell-Baeza A, Lavie CJ (2020) Physical exercise as therapy to fight against the mental and physical consequences of COVID-19 quarantine: special focus in older people. Prog Cardiovasc Dis S0033-0620(20):30063-30063. https://doi. org/10.1016/j.pcad.2020.03.009

3. Schwellnus M, Soligard T, Alonso J-M, et al (2016) How much is too much? (Part 2) International Olympic Committee consensus statement on load in sport and risk of illness. Br J Sports Med 50: 1043 LP - 1052. https://doi.org/10.1136/bjsports-2016-096572

4. Alack K, Pilat C, Krüger K (2019) Current knowledge and new challenges in exercise immunology. Dtsch Z Sportmed 70:250260. https://doi.org/10.5960/dzsm.2019.391

5. Giammattei C, Banducci R, Pierami G, Tomasi A (2015) Acute effects of exercise on immunity. Sport Sci ASPETAR:306-312

6. Kakanis MW, Peake J, Brenu EW, Simmonds M, Gray B, Hooper SL, Marshall-Gradisnik SM (2010) The open window of susceptibility to infection after acute exercise in healthy young male elite athletes. Exerc Immunol Rev 16:119-137

7. Aspen Institute (2020) Return to play: COVID-19 risk assessment tool. In: Aspen Inst. https://www.aspeninstitute.org/publications/ return-to-play-covid-19-risk-assessment-tool/

8. Campbell JP, Turner JE (2018) Debunking the myth of exerciseinduced immune suppression: redefining the impact of exercise on immunological health across the lifespan. Front Immunol 9:648

9. Palmowski J, Boßlau TK, Ryl L et al (2019) Managing immune health in sports - a practical guide for athletes and coaches. Dtsch Z Sportmed 70:219-226. https://doi.org/10.5960/dzsm.2019.389

10. Luzi L, Radaelli MG (2020) Influenza and obesity: its odd relationship and the lessons for COVID-19 pandemic. Acta Diabetol 57: 759-764. https://doi.org/10.1007/s00592-020-01522-8
11. Pinto AJ, Dunstan DW, Owen N, Bonfá E, Gualano B (2020) Combating physical inactivity during the COVID-19 pandemic. Nat Rev Rheumatol 16:1-2. https://doi.org/10.1038/s41584-0200427-z

12. Jukic I, Calleja-González J, Cos F, Cuzzolin F, Olmo J, Terrados N, Njaradi N, Sassi R, Requena B, Milanovic L, Krakan I, Chatzichristos K, Alcaraz PE (2020) Strategies and solutions for team sports athletes in isolation due to COVID-19. Sports 8:56. https://doi.org/10.3390/sports 8040056

13. Kramer A, Gollhofer A, Armbrecht G, Felsenberg D, Gruber M (2017) How to prevent the detrimental effects of two months of bed-rest on muscle, bone and cardiovascular system: an RCT. Sci Rep 7:13177. https://doi.org/10.1038/s41598-017-13659-8

14. Toresdahl BG, Asif IM (2020) Coronavirus disease 2019 (COVID19): considerations for the competitive athlete. Sports Health 12: 221-224. https://doi.org/10.1177/1941738120918876

15. Myer GD, Faigenbaum AD, Cherny CE, Heidt RS Jr, Hewett TE (2011) Did the NFL lockout expose the Achilles heel of competitive sports? J Orthop Sport Phys Ther 41:702-705. https://doi.org/10. 2519/jospt.2011.0107

16. Macdonald P (2020) Premier League: players face " $25 \%$ increased injury risk." In: BBC Sport. https://www.bbc.com/sport/football/ 52754212. Accessed 27 May 2020

17. Primorac D, Matišić V, Molnar V, Bahtijarević Z, Polašek O (2020) Pre-season football preparation in the era of COVID-19: Croatian Football Association Model. J Glob Health 10:10352. https://doi. org/10.7189/jogh.10.010352

18. Buldú JM, Antequera DR, Aguirre J (2020) The resumption of sports competitions after COVID-19 lockdown: the case of the Spanish football league. Chaos Solitons Fractals 109964:109964. https://doi.org/10.1016/j.chaos.2020.109964

19. Eirale C, Bisciotti G, Corsini A, Baudot C, Saillant G, Chalabi H (2020) Medical recommendations for home-confined footballers' training during the COVID-19 pandemic: from evidence to practical application. Biol Sport 37:203-207. https://doi.org/10.5114/ biolsport.2020.94348

20. Ford JM, Campbell KR, Ford CB et al (2018) Can functional movement assessment predict football head impact biomechanics? Med Sci Sports Exerc 50:1233-1240. https://doi.org/10.1249/MSS. 0000000000001538

21. Milanović Z, Pantelić S, Čović N, Sporiš G, Krustrup P (2015) Is recreational soccer effective for improving VO2 max a systematic review and meta-analysis. Sports Med 45:1339-1353. https://doi. org/10.1007/s40279-015-0361-4

22. Haddad M, Stylianides G, Djaoui L, Dellal A, Chamari K (2017) Session-RPE method for training load monitoring: validity, ecological usefulness, and influencing factors. Front Neurosci 11:612. https://doi.org/10.3389/fnins.2017.00612

23. Mattioli AV, Ballerini Puviani M, Nasi M, Farinetti A (2020) COVID-19 pandemic: the effects of quarantine on cardiovascular risk. Eur J Clin Nutr 74:1-4. https://doi.org/10.1038/s41430-0200646-z

24. Narici M, De Vito G, Franchi M et al (2020) Impact of sedentarism due to the COVID-19 home confinement on neuromuscular, cardiovascular and metabolic health: physiological and pathophysiological implications and recommendations for physical and nutritional countermeasures. Eur J Sport Sci:1-22. https://doi.org/10. 1080/17461391.2020.1761076

25. Lim MA, Huang I, Yonas E, et al (2020) A wave of non-communicable diseases following the COVID-19 pandemic. Diabetes Metab Syndr Clin Res Rev 14:979-80. https://doi.org/10.1016/j. dsx.2020.06.050

26. Huang I, Pranata R, Lim MA, et al (2020) C-reactive protein, procalcitonin, D-dimer, and ferritin in severe coronavirus disease2019: a meta-analysis. Ther Adv Respir Dis. https://doi.org/10. $1177 / 1753466620937175$ 
27. Lim MA, Pranata R, Huang I, et al (2020) Multiorgan Failure With Emphasis on Acute Kidney Injury and Severity of COVID-19: Systematic Review and Meta-Analysis. Can J Kidney Heal Dis. https://doi.org/10.1177/2054358120938573

28. Pranata R, Lim MA, Huang I, et al (2020) Hypertension is associated with increased mortality and severity of disease in COVID-19 pneumonia: a systematic review, meta-analysis and meta-regression. JRAAS - J Renin-Angiotensin-Aldosterone Syst 1-11. https://doi.org/10.1177/14703203209268

29. Huang I, Lim MA, Pranata R (2020) Diabetes mellitus is associated with increased mortality and severity of disease in COVID-19 pneumonia - a systematic review, meta-analysis, and meta-regression: diabetes and COVID-19. Diabetes Metab Syndr Clin Res Rev 14:395-403. https://doi.org/10.1016/j.dsx.2020.04.018

30. Pranata R, Huang I, Lim MA, Wahjoepramono EJ, July J (2020) Impact of cerebrovascular and cardiovascular diseases on mortality and severity of COVID-19 - systematic review, meta-analysis, and meta-regression. J Stroke Cerebrovasc Dis 29:104949. https://doi. org/10.1016/j.jstrokecerebrovasdis.2020.104949

31. Pranata R, Huang I, Lukito AA, Raharjo SB (2020) Elevated Nterminal pro-brain natriuretic peptide is associated with increased mortality in patients with COVID-19: systematic review and meta- analysis. Postgrad Med J postgradmedj-2020-137884. https://doi. org/10.1136/postgradmedj-2020-137884

32. Pranata R, Soeroto AY, Huang I et al (2020) Effect of chronic obstructive pulmonary disease and smoking on the outcome of COVID-19. Int J Tuberc Lung Dis. https://doi.org/10.5588/ijtld. 20.0278

33. Goethals L, Barth N, Guyot J, Hupin D, Celarier T, Bongue B (2020) Impact of home quarantine on physical activity among older adults living at home during the COVID-19 pandemic: qualitative interview study. JMIR aging 3:e19007. https://doi.org/10.2196/ 19007

34. Cai Q, Huang D, Ou P, et al (2020) COVID-19 in a designated infectious diseases hospital outside Hubei Province, China. medRxiv 2020.02.17.20024018. https://doi.org/10.1101/2020.02. 17.20024018

35. Pastora-Bernal JM, Martín-Valero R, Barón-López FJ, EstebanezPérez MJ (2017) Evidence of benefit of telerehabitation after orthopedic surgery: a systematic review. J Med Internet Res 19:e142. https://doi.org/10.2196/jmir.6836

Publisher's note Springer Nature remains neutral with regard to jurisdictional claims in published maps and institutional affiliations. 